\title{
Relationships between Artemisia ordosica communities and environmental factors following sand-dune stabilization in the Mu Us desert, northwest China
}

\author{
Dongqing Fan ${ }^{1,2} \cdot$ Yuqing Zhang ${ }^{1,2} \cdot$ Shugao Qin ${ }^{1,2} \cdot \operatorname{Bin} \mathrm{Wu}^{1,2}$
}

Received: 30 December 2014/ Accepted: 16 November 2015/Published online: 23 June 2016

(C) The Author(s) 2016. This article is published with open access at Springerlink.com

\begin{abstract}
Artemisia ordosica is an excellent sand-fixing shrub for sand stabilization in northwestern China. Sand dune stabilization, a critically important process, leads changes in abiotic factors, such as soil structure and nutrient contents. However, the effects of factors on an $A$. ordosica community following sand stabilization remain unclear. In this study, we used canonical correspondence analysis (CCA) to examine the relationships between $A$. ordosica communities and environmental factors at three habitats: semi-fixed dune (SF), fixed dune with low-coverage biological soil crust (F), and fixed dune with highcoverage biological soil crust (FC) in Mu Us desert. The mean height and coverage of plants increased with sand stabilization, while species diversity and richness increased initially and then reduced significantly. Correlation analysis and CCA revealed that slope, soil organic carbon, and nutrient contents, proportion of fine soil particles, soil moisture, and thickness of biological soil crust were all
\end{abstract}

Project funding: This work was supported by the National Basic Research Program of P. R. China (973 Program, 2013CB429901), the Fundamental Research Funds for the Central Universities of P.

R. China (BJFU-TD2011-04), and National Technology and Science Support Program of P. R. China (2012BAD16B02).

The online version is available at http://www.springerlink.com

Corresponding Editor: Hu Yanbo

Shugao Qin

qinshugao@gmail.com

1 Yanchi Research Station, School of Soil and Water Conservation, Beijing Forestry University, Beijing, China

2 Key Laboratory of Soil and Water Conservation and Desertification Combating of the Ministry of Education, Beijing Forestry University, Beijing, China highly correlated with vegetation characteristics. These environmental factors could explain $40.42 \%$ of the vegetation-environment relationships at the three habitats. The distribution of plant species was positively related to soil moisture in the SF dune. Soil moisture, soil nutrient, and fine-particle contents mainly affected plants distribution in the F dune. In the FC dune, distribution of plant species was positively and negatively correlated with the thickness of biological soil crust and soil moisture at a depth $0-20 \mathrm{~cm}$, respectively. The dominance value of typical steppe species increased significantly following sand-dune stabilization and relations between species and samples in CCA ordination bi-plots showed that perennial grasses could invade the A. ordosica community on FC, indicating A. ordosica communities had a tendency to change into typical steppe vegetation with the further fixation. We conclude that the significant differentiation not only occurred in community characteristics, but also in the relationships between vegetation and environmental factors among the three stages of dune fixation. So, restoration of degraded dune ecosystems should be based on habitat conditions and ecological needs.

Keywords Artemisia ordosica - Canonical correspondence analysis · Environmental factor $\cdot$ Mu Us desert $\cdot$ Sand dune stabilization

\section{Introduction}

The interaction between plants and the environment generates plant communities, and multiple environmental factors affect the spatial distribution of those communities (Borcard et al. 1992). Studies of the relationship between sand-dune vegetation and environmental factors have 
shown that soil properties, topography, and underground water level are the main factors leading to changes in vegetation (Qian et al. 2007; Stavi et al. 2008; Sang 2009). However, the distribution of vegetation is often associated with corresponding environmental conditions (Beyer et al. 1998). For plant communities on sand dunes with the same climatic conditions, differences in habitat conditions following sand-dune stabilization may be the main cause of differences in the species composition and spatial distribution of plant communities (Li et al. 2010, 2011a).

Whether the relationships between distribution of plant species and environmental factors remain constant under different habitat conditions is still unclear. In addition, vegetation coverage and species diversity are two important features of plant communities. Many studies have shown that the impact of environmental factors on these two features is rather complex (Kerley et al. 2004; Song et al. 2011). In-depth analysis of the relationships between the vegetation characteristics (including vegetation distribution, vegetation coverage, and plant-species diversity) and environmental factors during sand stabilization can provide important information related to the management of desert vegetation communities, and protection and restoration of arid and semi-arid sand dune ecosystems.

China is a country that suffers from serious desertification: some $27.33 \%$ of China's total land area has become desert (State Forestry Administration 2011). A wide range of vegetation restoration programs have been carried out to control desertification in northwest China ( $\mathrm{Li}$ et al. 2004). The Mu Us desert is situated in the arid and semi-arid ecotones of northern China. This special ecogeographic location is the key region where preventative work on desertification is highlighted (Yang et al. 2012). In the Mu Us desert, Artemisia ordosica is an excellent sand-binding shrub that grows on dunes with various degrees of sand mobility (Li 2001; Li et al. 2011a).

However, it is difficult to determine the stability of an $A$. ordosica community, which is important for vegetation management and ecological security maintenance ( $\mathrm{Li}$ et al. 2011a). Current studies have mainly emphasized the composition of plants and their dynamics in A. ordosica communities, and have not comprehensively considered the variations in soil physical and chemical properties, soil moisture, the physiological and ecological characteristics of the A. ordosica community, and the dynamic characteristics of the population following sand-dune fixation (Gao et al. 1999; Li 2005; Li et al. 2011a). Differences in plant responses to environmental factors lead to changes in community distribution. Therefore, the changes in the relationship between the A. ordosica community and the environment still require further study.

Quantitative analysis provides an important method for ecological research related to vegetation, and gradient analysis is the most widely used method in plant ecological studies (Song et al. 2009; Kent 2011; Khan et al. 2013). Gradient analysis is a technique of ordination, in which the quadrats (or plant species) are arranged in a certain space, so that the ordination axis can reflect certain ecological gradients. These gradients are used to explain the relationship between the vegetation conditions, including species composition and spatial distribution, and environmental factors.

In this study, basic characteristics of the A. ordosica communities and environmental factors at sites with different degrees of dune stabilization were investigated, and the relationships between plant distribution within the communities and environmental factors were analyzed using gradient analysis. Our objectives were to: investigate which environmental factors primarily affect the coverage and species composition of plants within A. ordosica communities; identify the main environmental factors affecting the distribution of plant species within the communities at different stages of sand fixation; and understand the effects of the environmental driving forces on the succession of A. ordosica communities. We hypothesized that the dominant environmental factors affecting the $A$. ordosica community vary following sand stabilization. Quantitative analysis to characterize A. ordosica communities shows that they tend to change into typical steppe vegetation following sand-dune stabilization.

\section{Materials and methods}

\section{Study area}

The study area was located in the Yanchi Research Station of Beijing Forestry University, in Ningxia, northwest China. The area lies on the southern edge of the Mu Us desert $\left(37^{\circ} 42^{\prime} \mathrm{N}, 107^{\circ} 14^{\prime} \mathrm{E} ; 1400-1800 \mathrm{~m}\right.$ above sea level) and is characterized by a mid-temperate semi-arid continental monsoon climate. The mean annual precipitation (1954-2013) is $275 \mathrm{~mm}$, the mean annual temperature is $8.1^{\circ} \mathrm{C}$ (Wang et al. 2014), and the mean annual potential evapotranspiration is $2024 \mathrm{~mm}$ (Jia et al. 2014). The soil is aeolian sandy soil with a $\mathrm{pH}$ range of $8.5-8.8$.

Vegetation in the station mainly comes from air seeding and afforestation for desertification control in the 1980s. After nearly 30 years, the dominant vegetation on the sand dunes is A. ordosica communities with some desert leguminous shrubs, xeric grass, and herbs.

\section{Vegetation survey and soil sampling analysis}

From July to August 2013, three $100 \mathrm{~m} \times 100-\mathrm{m}$ plots were established in the study area. All the plots were 
covered by A. ordosica communities without anthropogenic interference. One plot was located in a semi-fixed sand dune (SF), one in a fixed dune with low coverage of biological soil crust $(<20 \%, \mathrm{~F})$, and one in a fixed dune with high coverage biological soil crust $(>50 \%, \mathrm{FC})$. In each plot, $501 \mathrm{~m} \times 1-\mathrm{m}$ survey quadrats were randomly established, totaling 150 quadrats. The number of plant species, abundance of each species, and plant height and coverage were determined in each survey quadrat.

A geological compass was used to measure the degree and direction of slope. Thickness of biological soil crust on the land was measured using calipers, and biological soil-crust coverage was measured with a 10-pin point sampling frame (Li et al. 2005). Soil bulk densities $\left(\gamma_{\mathrm{s}}\right)$ were measured using a soil-cutting ring (diameter, $5 \mathrm{~cm}$ ), within each quadrat at a soil layer of $0-20-\mathrm{cm}$ depth. Then soil samples were collected within each quadrat at a depth of $0-20 \mathrm{~cm}$ by using a soil auger (diameter, $3 \mathrm{~cm}$ ). Additional soil cores were taken with the same soil auger in each quadrat to measure soil water content (SW) at depths of $0-20 \mathrm{~cm}$ (SW1), 20-40 cm (SW2), and 40-60 cm (SW3). Soil samples were air-dried and handsieved through a $2 \mathrm{~mm}$ screen to remove roots and other debris. The pretreated soil samples were analyzed with a laser diffraction technique using Malvern (MS 2000) to measure the topsoil particles and fractal characteristics (Gao et al. 2014). Each sample was measured five times and the mean value was used. The soil particle size distribution (PSD) results were output by U.S. Soil Taxonomy in the following size grades: $0-2,2-50,50-100$, 100-250, 250-500, 500-1000, and 1000-2000 $\mu \mathrm{m}$. Soil $\mathrm{pH}$ was measured using a pHS-3C laboratory $\mathrm{pH}$ meter (Dazhong Analytical Instruments Factory, Shanghai, China). Soil electrical conductivity was measured using a DDS-11A laboratory conductivity meter (Shanghai Lida Instrument Co., Shanghai, China), soil organic carbon (SOC) was measured using the potassium dichromate oxidation-external heating method, and soil total nitrogen (TN) content and total phosphorus (TP) content were measured using a Kjeldahl apparatus (FOSS 2200) and a Shimadzu UV-2550 UV spectrophotometer (Shimadzu Corp. Kyoto, Japan), respectively. All field sampling and measurements were repeated three times.

\section{Data analysis}

\section{Calculation of dominance of species}

The dominance value of each species was calculated using Formula (1) (Zuo et al. 2009):

$D V=(R A+R H+R C) / 3$ where $D V$ is the dominance of a species; $R A$ is the species relative abundance (\%); $R H$ is the species' relative height $(\%)$; and $R C$ is the species relative coverage (\%).

\section{Calculation of species diversity index}

Species richness $(R)$ was defined as the number of species in each survey quadrat $(s)$.

The Shannon-Wiener Index $(H)$ was calculated using Formula (2) (Li 2001):

$H=-\sum_{i=1}^{S} P i \ln P i$

where $S$ is the total number of species, and $P_{i}$ is the proportion of individual plants belonging to species $i$ in all individual plants.

The Simpson index was calculated using Formula (3):

Simpson index $=1-\sum_{i=1}^{S} P i^{2}$

where $S$ is the total number of species, and $P_{i}$ is the proportion of individual plants belonging to species $i$ in all individual plants.

\section{Calculation of fractal dimension}

Fractal dimension of soil PSD was calculated based on the volume distribution of soil particle size. The equation (Gui et al. 2010) is expressed using Formula (4):

$\frac{V\left(r<R_{i}\right)}{V_{T}}=\left(\frac{R_{i}}{R_{\max }}\right)^{3-D}$

where $r$ is the soil particle size, $R_{i}$ is the soil particle size of grade $i, R_{\max }$ is the maximum value of soil particle size, $V\left(r<R_{i}\right)$ is the volume of soil particle size less than $R_{i}, V_{T}$ is the total volume of soil particles, and $D$ is the volumebased fractal dimension.

\section{Canonical correlation analysis}

Canonical correlation analysis (CCA) was performed to examine the relationships between plant distribution and environmental factors in the three plots. To avoid the effect of redundant variables, the significance of species-environment correlation was tested by a Monte Carlo test $(P<0.05)$, then the significant environmental factors were used for CCA. A matrix composed of 150 quadrats and 12 environmental factors was constructed to analyze the relationships between the quadrat distribution and environmental factors. Another matrix composed of 24 species and 12 environmental factors was constructed to analyze the relationship between the distribution of plant species and environmental factors. 
In general, the coordinates (scores) of ordination objects (quadrat, species, and environmental factors) are only relative; they do not have absolute meanings. When interpreting ordination plots, the relative distance, relative direction, and the relative order of projection points were used to explain the relationships between the objects. An arrow denotes the direction of maximum environmental factor change, and the length of the arrow represents the degree of the influence of the environmental factor on the species data (explanatory power).

The angle between the arrows represents the correlations between the factors. A smaller angle indicates a stronger correlation. If the angle is close to a right angle, the correlation is very small. Two arrows pointing in the same direction represent a positive correlation between factors, while arrows pointing in opposite directions represent negative correlation (ter Braak 1986).

Species are denoted using triangles and the corresponding acronyms. The relative distance between the species and quadrat was used to assess changes in the relative abundance of a species within the quadrat. Closer distances between the species and the quadrat indicated a higher relative abundance of the species in that particular quadrat. Projections were made from the quadrat points to the environmental factor arrows, and the positions of the projection points approximately represent the rank of the environmental factors in these quadrats. The relative positions of the projection of the species point to environmental factor arrows that represent the rank of the optimum value of the species for the corresponding environmental factors.

\section{Statistical analysis}

After a homogeneity of variance test $(P>0.05)$, univariate analysis of variance (ANOVA) and multiple comparison tests $(P<0.01)$ were performed to compare the community characteristics of species diversity in different stages of sand-dune stabilization. Univariate ANOVA and least-significant difference (LSD) multiple comparisons were performed using SPSS 18.0 for Windows. ShannonWiener $(H)$ and Simpson indices, Monte Carlo test and CCA were calculated using the R 3.0.1 Vegan package $(2.0-10)$

\section{Results}

\section{Vegetation characteristics of $A$. ordosica communities}

Table 1 showed the differences in species number, average height, vegetation cover, Shannon-Wiener index, Simpson index, and biological soil crust among the three dune plots $(P<0.01)$. The average height and coverage of plants within the communities increased from SF to FC dunes. The Shannon-Wiener and Simpson indices of the communities were lower on the FC dune than on the SF and F dunes. The biological soil-crust conditions differed significantly following sand stabilization, and the biological soil crust thickness gradually increased with dune fixing.

Table 2 showed the plant species dominance values in the three sand stabilization stages. Within the communities, dominant species were A. ordosica and Chenopodium aristatum on the SF dune, and A. ordosica and Leymus secalinus on the $\mathrm{F}$ and $\mathrm{FC}$ dunes. The dominance value of A. ordosica increased from $25.60 \%$ on the SF dune and $26.64 \%$ on the F dune to $30.45 \%$ on the FC dune. The dominance of $C$. aristatum and Corispermum puberulum was relatively high on the SF dune $(18.97 \%)$. With sand fixing, the dominance value of $C$. aristatum and $C$. puberulum fell to $0.95 \%$ on the F dune and $3.27 \%$ on the FC dune. Pennisetum centrasiaticum and $L$. secalinus had rather high dominance values on the FC dune, and those species occurred in addition to A. ordosica.

\section{Relationships between vegetation characteristics and environmental factors within $\boldsymbol{A}$. ordosica communities}

Correlation analysis among vegetation characteristics, soil factors, and topography are shown in Table 3. Vegetation coverage was significantly correlated with all soil factors, aside from soil $\mathrm{pH}$ and electrical conductivity. Species richness and surface-soil crust thickness was negatively correlated $(P<0.01)$. Vegetation coverage and species richness were both positively correlated with soil-particle structure factors (soil clay content, soil silt content, soil PSD) and soil nutrient factors, including TN, TP, and SOC, and were both negatively correlated with soil moisture.

\section{Canonical correspondence analysis on plant distribution and environmental factors within $A$. ordosica communities}

The relationships between distribution of plant species and environment factors (excluding uncorrelated environment factors) following sand-dune stabilization were obtained by performing CCA analysis (Fig. 1a, b). Species-environmental relationships (Table 4; Fig. 1) revealed that the correlation was relatively high on the first two canonical axes, where all environmental factors could explain $40.42 \%$ of the species-environmental relationships.

Using partial CCA analysis the explanatory powers of topographical factors, soil factors, and the interaction 
Table 1 Vegetation characteristics of Artemisia ordosica communities following sand dune stabilization

\begin{tabular}{lllllll}
\hline Dune type & Species number & Average height $(\mathrm{cm})$ & Vegetation cover $(\%)$ & Shannon index $(\mathrm{H})$ & Simpson index & $\begin{array}{l}\text { Thickness of biological } \\
\text { soil crust }(\mathrm{mm})\end{array}$ \\
\hline SF & 16 & $34.90 \pm 0.02^{\mathrm{a}}$ & $36.60 \pm 0.01^{\mathrm{a}}$ & $1.34 \pm 0.05^{\mathrm{a}}$ & $0.66 \pm 0.02^{\mathrm{a}}$ & $0.81 \pm 0.25^{\mathrm{a}}$ \\
$\mathrm{F}$ & 20 & $65.40 \pm 0.13^{\mathrm{b}}$ & $50.10 \pm 0.01^{\mathrm{b}}$ & $1.40 \pm 0.04^{\mathrm{a}}$ & $0.68 \pm 0.01^{\mathrm{a}}$ & $2.43 \pm 0.16^{\mathrm{b}}$ \\
$\mathrm{FC}$ & 13 & $80.40 \pm 0.02^{\mathrm{c}}$ & $66.20 \pm 0.01^{\mathrm{c}}$ & $1.12 \pm 0.05^{\mathrm{b}}$ & $0.60 \pm 0.02^{\mathrm{b}}$ & $6.73 \pm 0.37^{\mathrm{c}}$ \\
\hline
\end{tabular}

$S F$ semi-fixed sand dune, $F$ fixed dune with little biological soil crust, $F C$ fixed dune with much biological soil crust

Values are mean $\pm \mathrm{SE}$; Values with different letters within columns are significantly difference at $P<0.01$

Table 2 Species dominance values in the different stages of dune stabilization

\begin{tabular}{|c|c|c|c|c|c|}
\hline Species & Ab. & Life-form & SF & $\mathrm{F}$ & $\mathrm{FC}$ \\
\hline Artemisia ordosica & Aro & $S$ & 25.60 & 26.64 & 30.45 \\
\hline Hedysarum mongolicum & Hem & S & 7.52 & 5.36 & 6.06 \\
\hline Leymus secalinus & Les & $\mathrm{P}$ & 11.40 & 23.50 & 24.42 \\
\hline Pennisetum centrasiaticum & Pec & $\mathrm{P}$ & 3.63 & & 12.70 \\
\hline Ixeridium graminifolium & Ixg & $\mathrm{P}$ & 3.68 & 2.15 & 2.72 \\
\hline Setaria viridis & Sev & A & 4.30 & 2.68 & 7.56 \\
\hline Heteropappus altaicus & Hea & $\mathrm{P}$ & 2.09 & 2.55 & 2.46 \\
\hline Cynanchum thesioides & Cyt & $S$ & 2.12 & 2.84 & 3.60 \\
\hline Euphorbia humifusa & Euh & A & 1.32 & 0.83 & 1.07 \\
\hline Chenopodium aristatum & Cha & A & 13.97 & 0.95 & 1.45 \\
\hline Corispermum puberulum & Cop & A & 5.00 & & 1.82 \\
\hline Cynanchum komarovii & Cyk & $S$ & 4.14 & & \\
\hline Sophora alopecuroides & Soa & $S$ & 2.80 & 4.42 & \\
\hline Caragana korshinskii & Cak & $S$ & & 3.37 & \\
\hline Astragalus melilotoides & Asm & $P$ & & 5.25 & \\
\hline Stipa breviflora & Stb & $P$ & 2.16 & 2.17 & 4.21 \\
\hline Cleistogenes squarrosa & Cls & $\mathrm{P}$ & 1.75 & 1.58 & 1.48 \\
\hline Eragrostis minor & Erm & A & 0.92 & 0.74 & \\
\hline Thermopsis lanceolate & Thl & $\mathrm{P}$ & 2.16 & 4.36 & \\
\hline Hedysarum scoparium & Hes & $S$ & & 3.33 & \\
\hline Phragmites australis & Pha & A & 2.50 & 4.47 & \\
\hline Salsola collina & Sac & A & 1.34 & & \\
\hline Agriophyllum squarrosum & Ags & A & 1.60 & & \\
\hline Cynanchum chinense & Сус & $\mathrm{P}$ & & 2.81 & \\
\hline
\end{tabular}

$S F$ semi-fixed sand dune, $F$ fixed dune with little biological soil crust, $F C$ fixed dune with much biological soil crust, $A$ annual grass and herbs, $P$ perennial grass and herbs, $S$ shrub (subshrub); Dominance values are presented as percent values between the two on species distribution were 13.03, 19.43, and $7.96 \%$, respectively (Fig. 2).

The CCA ordination biplots characterize how plant coverage and species richness are simultaneously distributed along the quadrats and species (Fig. 1a, b). Most F and FC quadrats were associated with the direction of plant coverage that increased, in which the characteristic species are A. ordosica, L. secalinus, and $P$. centrasiaticum Agriophyllum. Species richness was correlated with most F quadrats and the characteristic species are Astragalus melilotoides, Thermopsis lanceolata, and Sophora alopecuroides.

\section{Discussion}

\section{Changes in vegetation coverage and species richness within $A$. ordosica communities}

Our results showed that vegetation coverage and species richness within the $A$. ordosica communities are significantly correlated with soil factors. The vegetation coverage increased as the sand dune was stabilized, whereas species richness first increased and then decreased (Table 3; Fig. 1). Many studies have found vegetation coverage increases following sand-dune stabilization in arid and 


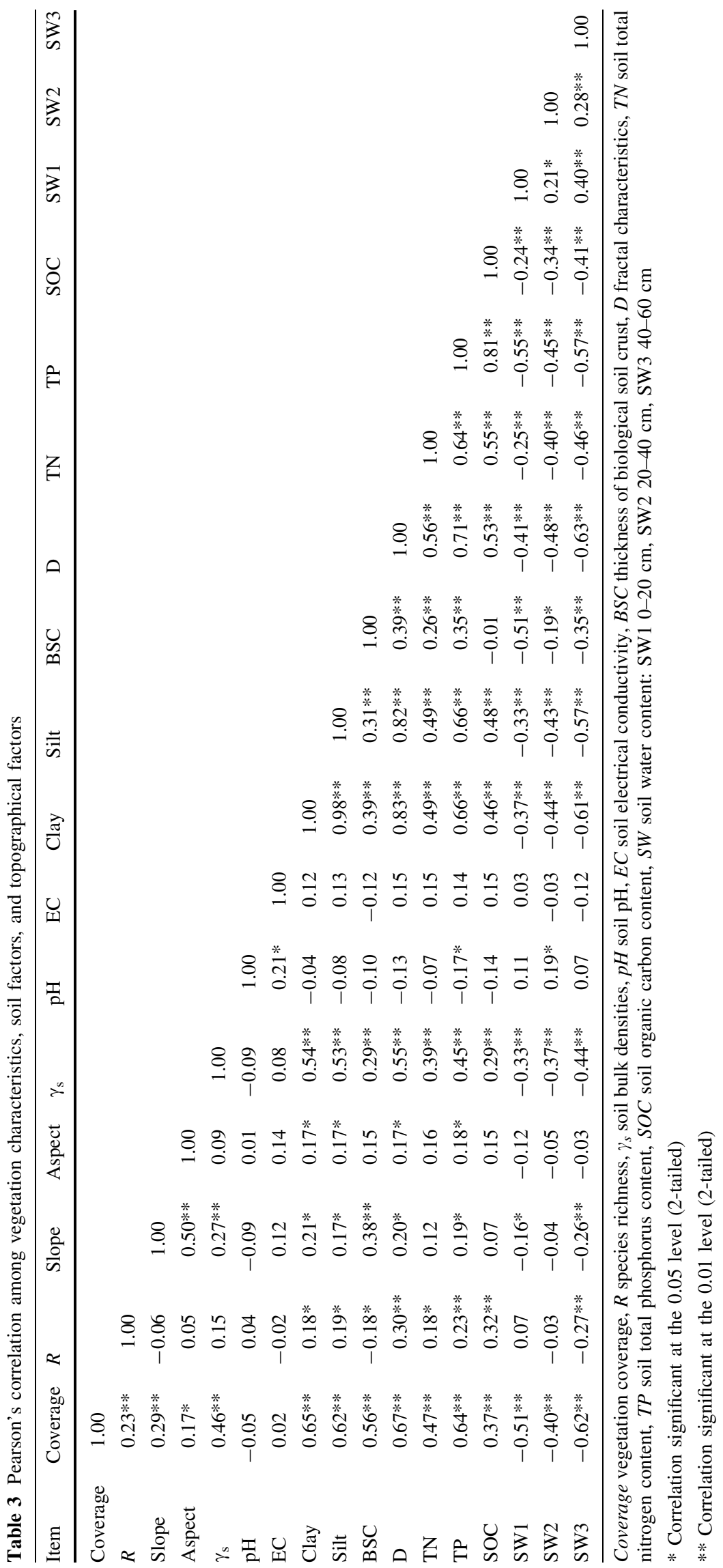




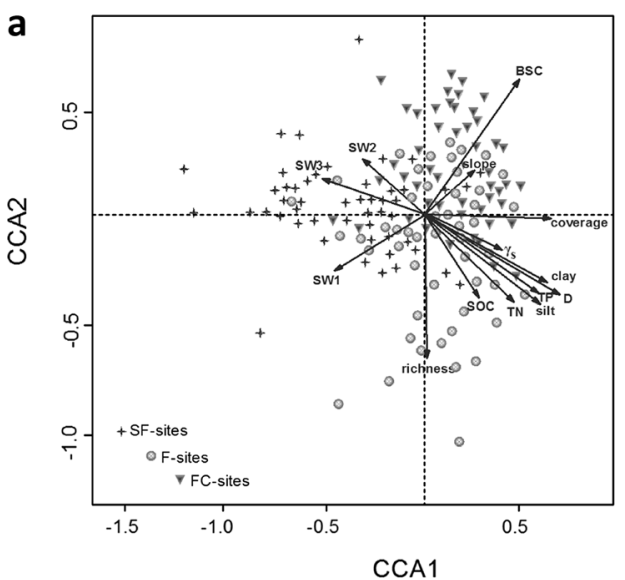

Fig. 1 CCA two-dimensional ordination diagram of the first two axes. This diagram addresses, includes the coordinates of quadrats and environmental factors in the ordination space (a); the overall correlation between the environmental factors and species distribution (b). The diagram a shows that there is a notable separation of sampling quadrats depending on the dune fixation stage associated with environmental factors, which can be combined together with (b), which shows a separated distribution of plant species with environmental factors. Most SF quadrats were associated with the soil water content, in which the relative abundances of Agriophyllum squarrosum

Table 4 Monte Carlo test for the significance of environmental factors and species distribution

\begin{tabular}{lrrll}
\hline Items & CCA1 & CCA2 & $r^{2}$ & $P$ \\
\hline Coverage & 1.00 & 0.04 & 0.15 & 0.001 \\
$R$ & 0.01 & -1.00 & 0.12 & 0.001 \\
Slope & 0.72 & 0.69 & 0.06 & 0.001 \\
Aspect & 0.98 & -0.18 & 0.01 & 0.129 \\
$\gamma_{\mathrm{s}}$ & 0.91 & -0.42 & 0.07 & 0.001 \\
pH & -0.53 & -0.85 & 0.02 & 0.067 \\
EC & 0.03 & -1.00 & 0.01 & 0.121 \\
Clay & 0.89 & -0.46 & 0.18 & 0.001 \\
Silt & 0.79 & -0.61 & 0.20 & 0.001 \\
BSC & 0.57 & 0.82 & 0.30 & 0.001 \\
D & 0.87 & -0.50 & 0.23 & 0.001 \\
TN & 0.71 & -0.71 & 0.15 & 0.001 \\
TP & 0.83 & -0.56 & 0.18 & 0.001 \\
SOC & 0.53 & -0.85 & 0.10 & 0.001 \\
SW1 & -0.83 & -0.56 & 0.11 & 0.001 \\
SW2 & -0.73 & 0.69 & 0.06 & 0.001 \\
SW3 & -0.95 & 0.30 & 0.10 & 0.001 \\
\hline Abbreviaton & & & &
\end{tabular}

Abbreviations as in Table 3; Monte Carlo tests to select significant environmental variables $(P<0.05)$; Monte Carlo permutation test simulation is run 999 times

semi-arid regions (Li 2005; Song et al. 2011; Li et al. 2014). With sand fixation, Liu et al. (2004) observed plant species richness would first increase and then decrease or would simply remain unchanged, whereas Baniya et al. (2009) reported that species richness gradually increases.

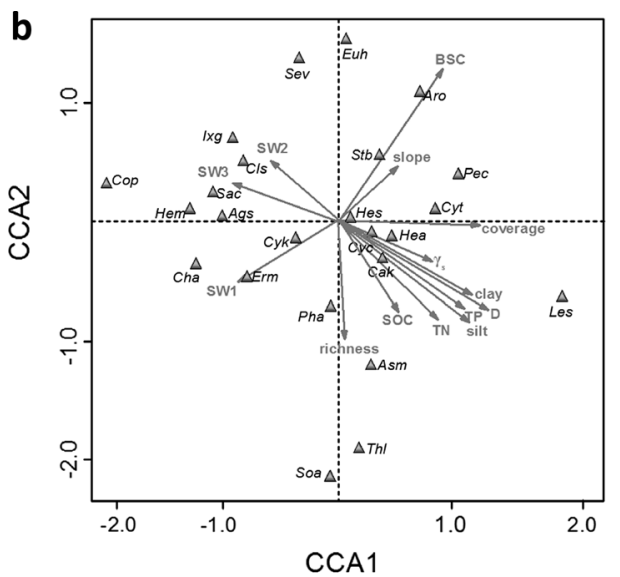

and Corispermum puberulum were high. Most $\mathrm{F}$ quadrats were associated with soil water content, soil nutrient factors, and structure of fine soil particles, in which the relative abundances of Astragalus melilotoides, Thermopsis lanceolata, and Leymus secalinus were high. Most FC quadrats were associated with the thickness of the surface soil crust and the slope, in which A. ordosica, Stipa breviflora, and Pennisetum centrasiaticum had relatively high abundances. The species abbreviations and environmental variables can be seen in Tables 2 and 3

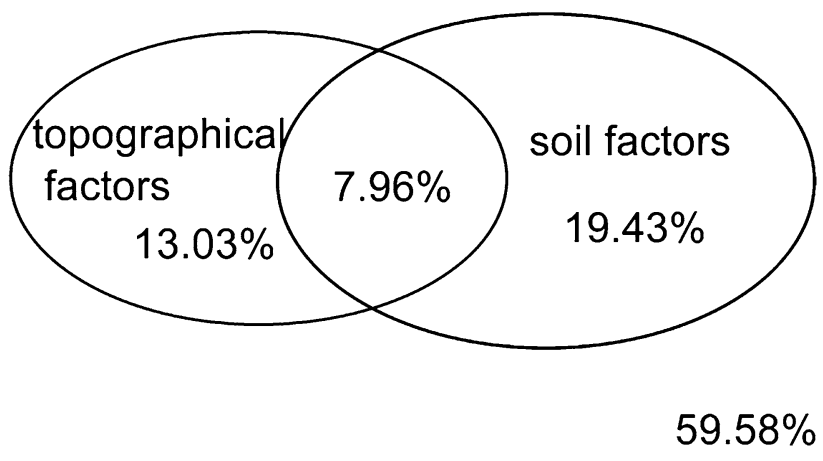

Fig. 2 Venn diagram of contributions of different environmental factors to the distribution of species

We found that the highest plant species richness within the A. ordosica community occurred at the $\mathrm{F}$ stage, rather than at the FC stage. Why did this occur? In the F dunes, there were moderate soil moisture and nutrient conditions, and soil heterogeneity following sand fixation, which were similar to intermediate disturbance habitats (Connell 1978; Catford et al. 2012). This kind of habitat could provide adequate opportunities and suitable environmental conditions for the colonization and survival of plants with different types and life forms (Bever 2003; Li 2005; Zuo et al. 2009; Song et al. 2011).

The balance of vegetation and soil moisture is very important to the formation of a stable vegetation system ( $\mathrm{Li}$ et al. 2014). Our study shows that vegetation coverage increased and soil moisture decreased with the sand-dune 
fixing. This suggests that, during sand-dune stabilization, increased vegetation coverage could lead to reduced soil moisture. Soil moisture was relatively high and soil nutrient contents were relatively low at the early stage of sand dune stabilization.

However, the converse conditions occurred in the fixed sand dune with high coverage and large thickness biological soil crusts at the late stage of sand dune stabilization. This suggests that there exists a threshold of vegetation coverage of A. ordosica communities during sand-dune stabilization, within which soil moisture and nutrient contents will both be sustainable. CCA ordination biplots shows that the threshold should appear during the transition from semi-fixed dunes to fixed dunes with high coverage biological soil crust. Therefore, we suggest that the threshold of vegetation coverage of A. ordosica communities may be about $50 \%$ in the study areas. However, accurately determining the carrying capacity thresholds of vegetation in different bioclimatic zones may still need long-term investigation on the relationships between vegetation conditions and soil resources.

\section{Changes in relationships between vegetation and environmental factors within $A$. ordosica communities}

At the early stage of sand dune stabilization, the distribution of plant species was positively correlated with soil moisture and negatively correlated with soil nutrient contents. In the latter stage of sand-dune stabilization, the correlations between vegetation and these two factors reversed.

On the SF dune, the low-coverage vegetation mainly consisted of annual sandy herbs (such as C. puberulum, Agriophyllum squarrosum) and pioneer perennial shrubs (such as A. ordosica), because there was sufficient soil moisture for plant growth ( $\mathrm{Li}$ et al. 2014). The distribution of plant species was significantly positively correlated with soil moisture on the SF dune $(P<0.05)$. As the sand dune stabilized, plant coverage, soil texture, and nutrient contents within A. ordosica communities rose, and the distribution of plant species was significantly positively correlated with soil texture and nutrient contents on the $\mathrm{F}$ dune $(P<0.05)$. At this stage, in the dune with low-coverage lichen or moss soil crusts, vegetation within $A$. ordosica communities consisted of sandy shrubs (such as $S$. alopecuroides, Hedysarum mongolicum), and xeric herbs and grass (such as T. lanceolata, Cleistogenes squarrosa), and coverage and species richness both increased. The plant community can improve the soil environment by capturing wind-driven fine soil materials and by increasing soil fertility through litterfall (Chapin et al. 2011), which would promote the growth of plants within the community by increasing water-holding capacity and nutrient availability of the soil on sand dunes. That is, the vegetation community co-develops with the soil environment following sand dune stabilization. In the late stage of dune stabilization, vegetation coverage of A. ordosica community tended to stabilize, and the biological soil crust expended and thickened gradually. The distribution of plant species was correlated with soil moisture, proportion of fine soil particles, soil nutrient contents, and the thickness of biological soil crust. At this stage, the biological soil crust affected the distribution of plant species significantly in the dune with high coverage biological soil crusts, due to its special hydrophysical characteristics and tough crust construction. Biological soil crust can reduce the rainfall infiltration to the subsoil and improve soil moisture in the topsoil, which is conducive to the survival and reproduction of shrubs and herbaceous plants with shallow roots (Li et al. 2011b); next, biological soil crust can also reduce seed germination, by preventing seeds from becoming covered with soil ( $\mathrm{Li}$ et al. 2005), which will reduce the update ability of A. ordosica community. These reasons together led to more perennial and typical steppe grasses were distributed in the A. ordosica community in the dune with high coverage biological soil crusts.

CCA ordination biplots (Fig. 1) showed that, following sand stabilization, the relative abundances of pioneer herbs (A. squarrosum, C. puberulum, etc.) decreased, whereas the relative abundance of perennial grass and other perennial herbs increased. A 50-year long-term study on the introduction of sand-fixing vegetation and rehabilitation of the soil environment in Shapotou of Ningxia showed that the sand-fixing plant community formed a complete community composed of sparse shrubs and many herbs ( $\mathrm{Li} 2005)$. This study revealed that, in the fixed sand dunes with extensive biological soil crust, the A. ordosica community tended to develop into an autochthonic community with many perennial grasses and herbs. This suggests that, with the interaction between artificial sand-fixing vegetation and the environment, the habitat in the sand dunes would be restored to the original habitat that existed before desertification. Therefore, shrub-planting for sand dune fixation is an effective approach to ecosystem restoration in the semiarid $\mathrm{Mu}$ Us desert.

\section{Conclusion}

The relationships between community characteristics (species diversity, species composition, and vegetation cover) and environmental factors show strong variation along stages of dune fixation, supporting our conclusion that restoration of degraded dune ecosystems should consider habitat conditions and ecological needs. This study 
also offers further evidence that $A$. ordosica communities tend to change into typical steppe vegetation following sand-dune stabilization, which helps us to apply these findings to management of semi-arid ecosystems.

Acknowledgments We thank Jiachen Zhang, Dong Chen, Hao Gao and Linfeng Zhu for their assistance with the field measurements. We also thank the language services company for their help with language revision, and valuable comments to the manuscript.

Open Access This article is distributed under the terms of the Creative Commons Attribution 4.0 International License (http://crea tivecommons.org/licenses/by/4.0/), which permits unrestricted use, distribution, and reproduction in any medium, provided you give appropriate credit to the original author(s) and the source, provide a link to the Creative Commons license, and indicate if changes were made.

\section{References}

Baniya CB, Solhøy T, Vetaas OR (2009) Temporal changes in species diversity and composition in abandoned fields in a transHimalayan landscape, Nepal. Plant Ecol 201(2):383-399

Bever JD (2003) Soil community feedback and the coexistence of competitors: conceptual frameworks and empirical tests. New Phytol 157:465-473

Beyer L, Tielbörger K, Blume HP, Pfisterer U, Pingpank K, Podlech D (1998) Geo-ecological soil features and the vegetation pattern in an arid dune area in the Northern Negev, Israel. Z für Pflanzenernährung Und Bodenkunde 161:347-356

Borcard D, Legendre P, Drapeau P (1992) Partialling out the spatial component of ecological variation. Ecology 73:1045-1055

Catford JA, Daehler CC, Murphy HT, Sheppard AW, Hardesty BD, Westcott DA, Rejmánek M, Bellingham PJ, Pergl J, Horvitz CC, Hulme PE (2012) The intermediate disturbance hypothesis and plant invasions: implications for species richness and management. Perspect Plant Ecol Evol Syst 14(3):231-241

Chapin FS III, Chapin MC, Matson PA, Vitousek P (2011) Principles of terrestrial ecosystem ecology. Springer, Berlin

Connell JH (1978) Diversity in tropical rain forests and coral reefs. Science 199:1302-1310

Gao QZ, Yang J, Wu LJ, Tian QS (1999) Relationship of photosynthetic characteristics of Artemisia ordosica and environmental factors in Hobq sandy land. J Desert Res 19(3):276-279 (in Chinese)

Gao GL, Ding GD, Wu B, Zhang YQ, Qin SG, Zhao YY, Bao YF, Liu YD, Wan L, Deng JF (2014) Fractal scaling of particle size distribution and relationships with topsoil properties affected by biological soil crusts. PLoS One 9(2):e88559

Gui DW, Lei JQ, Zeng FJ, Mu GJ, Zhu JT, Wang H, Zhang Q (2010) Characterizing variations in soil particle size distribution in oasis farmlands - a case study of the Cele Oasis. Math Comput Model 51:1306-1311

Jia X, Zha TS, Wu B, Zhang YQ, Gong JN, Qin SG, Chen GP, Qian D, Kellomäki S, Peltola H (2014) Biophysical controls on net ecosystem $\mathrm{CO}_{2}$ exchange over a semiarid shrubland in northwest China. Biogeosciences 11:1-15. doi:10.5194/bg-11$1-2014$
Kent M (2011) Vegetation description and data analysis: a practical approach. Wiley, UK

Kerley GIH, Whitford WG, Kay FR (2004) Effects of pocket gophers on desert soils and vegetation. J Arid Environ 58:155-166

Khan N, Shaukat SS, Ahmed M, Siddiqui MF (2013) Vegetationenvironment relationships in the forests of Chitral district Hindukush range of Pakistan. J For Res 24(2):205-216

Li XR (2001) Study on shrub community diversity of Ordos Plateau, Inner Mongolia, northern China. J Arid Environ 47(3):271-279

Li XR (2005) Influence of variation of soil spatial heterogeneity on vegetation restoration. Sci China Ser D Earth Sci 48(11): 2020-2031

Li XR, Ma FY, Xiao HL, Wang XP, Kim KC (2004) Long-term effects of revegetation on soil water content of sand dunes in arid region of Northern China. J Arid Environ 57:1-16

Li XR, Jia XH, Long LQ, Zerbe S (2005) Effects of biological soil crusts on seed bank, germination and establishment of two annual plant species in the Tengger Desert (N China). Plant Soil 277(1-2):375-385

Li SL, Werger MJA, Zuidema PA, Yu FH, Dong M (2010) Seedlings of the semi-shrub Artemisia ordosica are resistant to moderate wind denudation and sand burial in $\mathrm{Mu}$ Us sandland, China. Trees 24(3):515-521

Li SL, Yu FH, Werger MJA, Dong M, Zuidema PA (2011a) Habitatspecific demography across dune fixation stages in a semi-arid sandland: understanding the expansion, stabilization and decline of a dominant shrub. J Ecol 99(2):610-620

Li XR, Jia RL, Chen YW, Huang L, Zhang P (2011b) Association of ant nests with successional stages of biological soil crusts in the Tengger Desert, Northern China. Appl Soil Ecol 47:59-66

Li XR, Zhang ZS, Tan HJ, Gao YH, Liu LC, Wang XP (2014) Ecological restoration and recovery in the wind-blown sand hazard areas of northern China: relationship between soil water and carrying capacity for vegetation in the Tengger Desert. Sci China Life Sci 57(5):539-548

Liu MZ, Jiang GM, Yu SL, Li YK, Gao LM, Niu SL, Jiang CD, Peng Y (2004) Dynamics of plant community traits during an 18-year natural restoration in the degraded sandy grassland of Hunshandak Sandland. Acta Ecol Sin 24(8):1734-1740 (in Chinese)

Qian YB, Wu ZN, Zhang LY, Zhao RF, Wang XY, Li YM (2007) Spatial patterns of ephemeral plants in Gurbantünggüt Desert. Chin Sci Bull 52(22):3118-3127

Sang WG (2009) Plant diversity patterns and their relationships with soil and climatic factors along an altitudinal gradient in the middle Tianshan Mountain area, Xinjiang, China. Ecol Res 24:303-314

Song C, Liu G, Liu Q (2009) Spatial and environmental effects on plant communities in the Yellow River Delta, Eastern China. J For Res 20(2): 117-122

Song Y, Zhou C, Zhang W (2011) Vegetation coverage, species richness, and dune stability in the southern part of Gurbantünggüt Desert. Ecol Res 26(1):79-86

State Forestry Administration, P. R. China (2011) A bulletin of status quo of desertification and sandification in China. http://wenku. baidu.com/view/a6ef2cefaeaad1f346933f38.html

Stavi I, Ungar ED, Lavee H, Sarah P (2008) Surface microtopography and soil penetration resistance associated with shrub patches in a semiarid rangeland. Geomorphology 94:69-78

ter Braak C (1986) Canonical correspondence analysis: a new eigenvector method for multivariate director gradient analysis. Ecology 67:1167-1179 
Wang B, Zha TS, Jia X, Wu B, Zhang YQ, Qin SG (2014) Soil moisture modifies the response of soil respiration to temperature in a desert shrub ecosystem. Biogeosciences 11:259-268. doi:10. 5194/bg-11-259-2014

Yang Y, Eerdun Hasi, Sun BP, Du HS, Zhao Y, Zhong XJ (2012) Effects of different vegetation restoration types on soil nutrients in southern edge of $\mathrm{Mu}$ Us sandy land. Agric Sci Technol 13(8): $1708-1712$

Zuo XA, Zhao XY, Zhao HL, Zhang TH, Guo YR, Li YQ, Huang YX (2009) Spatial heterogeneity of soil properties and vegetation-soil relationships following vegetation restoration of mobile dunes in Horqin Sandy Land, Northern China. Plant Soil 318(1-2):153-167 